\title{
Celecoxib Down-Regulates the Hypoxia- Induced Expression of HIF-1 $\alpha$ and VEGF Through the PI3K/AKT Pathway in Retinal Pigment Epithelial Cells
}

\author{
Yi-zhou Sun Na Cai Ning-ning Liu
}

The Department of Ophthalmology, the First Affiliated Hospital of China Medical University, Shenyang, Liaoning Province, China

\section{Key Words}

Cyclooxygenase-2 inhibitor $\bullet$ Hypoxia-inducible factor $1 \alpha \cdot$ Vascular endothelial growth factor - PI3K/AKT pathway • Human retinal pigmented epithelial cells

\begin{abstract}
Background/Aims: The goal of this study was to detect the expression of hypoxia-inducible factor $1 \alpha$ (HIF-1 $\alpha$ ) and vascular endothelial growth factor (VEGF) in human retinal pigmented epithelial (RPE) cells treated with celecoxib, a selective cyclooxygenase-2 (COX-2) inhibitor, under hypoxic and normoxic conditions and to explore the signaling mechanism involved in regulating the hypoxia-induced expression of HIF-1 $\alpha$ and VEGF in RPE cells. Methods: D407 cells were cultured in normoxic or hypoxic conditions, with or without celecoxib or a PI3K inhibitor (LY294002). The anti-proliferative effect of celecoxib was assessed using the MTT assay. RT-PCR, Western blotting and ELISA were performed to detect the levels of PI3K, phosphorylated AKT (p-AKT), HIF-1 $\alpha$, VEGF and COX-2. Results: Celecoxib inhibited the proliferation of RPE cells in a dose-dependent manner. Celecoxib suppressed the expression of VEGF at both the mRNA and protein levels and decreased HIF-1 $\alpha$ protein expression. HIF- $1 \alpha$ activation was regulated by the PI3K/AKT pathway. The celecoxib-induced downregulation of HIF- $1 \alpha$ and VEGF required the suppression of the hypoxia-induced PI3K/AKT pathway. However, the down-regulation of COX-2 did not occur in cells treated with celecoxib. Conclusions: The antiangiogenic effects of celecoxib in RPE cells under hypoxic conditions resulted from the inhibition of HIF- $1 \alpha$ and VEGF expression, which may be partly mediated by a COX-2-independent, PI3K/AKT-dependent pathway.

\section{Introduction}

Choroidal neovascularization (CNV) is a major characteristic of wet age-related macular degeneration (AMD) and is one of the most common causes of irreversible blindness in people over 60 years old in western countries [1]. Recent studies indicate that CNV is 
a complex process in which the degeneration of retinal blood vessels in the elderly leads to tissue ischemia and hypoxia; therefore, hypoxia-mediated signaling is thought to be involved in the progression of the wet form of AMD [2]. A key transcriptional regulator of the hypoxic response is hypoxia-inducible factor (HIF), which consists of HIF- $1 \alpha$ and HIF- $1 \beta$ subunits. HIF- $1 \alpha$ is regulated by oxygen tension, whereas HIF- $1 \beta$ is constitutively expressed. Studies have indicated that HIF- $1 \alpha$ is an important oxygen sensor and plays a crucial role in vasculogenesis and angiogenesis. A particularly key HIF- $1 \alpha$ responsive gene, VEGF, encodes its transcriptional activity [3]. VEGF, a specific mitogen for endothelial cells, has been identified as a key mediator in the retina and CNV [4]. A number of studies have observed that retinal pigment epithelial (RPE) cell-derived VEGF plays a key role in the progression of CNV [5-7]. VEGF is also increased in the vitreous and CNV membranes of patients with AMD $[6,8]$. Based on these data, current anti-VEGF therapies have become effective primary treatments for neovascular AMD [9]. However, repeated intravitreal injections of anti-VEGF drugs (e.g., ranibizumab, bevacizumab) increase the risk of side effects, which have a high clinical cost $[10,11]$. With an efficiency of $60 \%-70 \%$ and disease progression still occurring in some patients receiving anti-VEGF treatment, the retinal VEGF levels are still not altered [12]. Thus, there may be other causative agents affecting VEGF expression in CNV.

The expression of VEGF can be induced by multiple cellular pathways. Hypoxia results in the expression of HIF- $1 \alpha$, which, in turn, induces VEGF expression. It is generally accepted that hypoxia regulates CNV through the induction of HIF-1 $\alpha$ and VEGF $[13,14]$. However, few studies have been conducted investigating the upstream signaling events activated by hypoxia and its effects on CNV. It has been well demonstrated that the serine/threonine kinase AKT is one of the primary upstream regulators of HIF- $1 \alpha$, and this signaling pathway plays a key role in cell proliferation, transformation, survival, tumor angiogenesis and growth. AKT is activated by a phosphoinositide 3-kinase (PI3K)-dependent signaling pathway [15, 16]. The accumulation of HIF- $1 \alpha$ protein and other cytokines during hypoxia are involved in the activation of the PI3K/AKT pathway. In hypoxic tumor cells, HIF-1 $\alpha$ expression can be facilitated by PI3K/AKT signaling. Abnormal PI3K/AKT signaling may result in increased or uncontrolled cell proliferation in tumors [17].

One possible candidate for disrupting the angiogenic signaling cascade upstream of HIF$1 \alpha$-VEGF expression is celecoxib, a Cox-2-selective inhibitor that has efficacy equivalent to that of non-selective NSAIDs but presents with fewer adverse gastrointestinal events $[18,19]$. Celecoxib presents with anti-inflammatory, anti-tumor and anti-angiogenic properties. One study found that celecoxib reduced VEGF production through the PI3K/AKT/HIF- $1 \alpha$ pathway in a murine hepatocarcinoma model [19] and induced apoptosis via the down-regulation of PI3K/AKT [20,21]. In ophthalmology, celecoxib has been experimentally shown to suppress VEGF expression in the cornea, the retina and CNV and to effectively reduce angiogenesis [22-24]. Celecoxib also has anti-proliferative effects in RPE cells, and it can cause cell cycle arrest, which provides a strong rationale for the use of celecoxib in the treatment of AMD [25]. However, the mechanisms, the target molecules and the role of the PI3K/AKT/HIF$1 \alpha$ pathway in CNV remain unknown. We hypothesized that celecoxib reduces VEGF levels thought the PI3K/AKT/HIF-1 $\alpha$ pathway in CNV. The purpose of this study was to examine the expression of related factors in RPE cells under normoxic and hypoxic conditions and to determine whether celecoxib treatment can suppress the expression of VEGF by inhibiting the PI3K/AKT/HIF-1 $\alpha$ pathway in CNV.

\section{Materials and Methods}

Cell culture and hypoxic treatment

Human RPE D407 cells were purchased from the Central Laboratory of Xiangya Central South University, China and were cultured in DMEM medium supplemented with 10\% FBS (heat inactivated), 1\% nonessential amino acids, $20 \mathrm{mM}$ HEPES, $29 \mathrm{mM}$ sodium bicarbonate, $100 \mathrm{U} / \mathrm{ml}$ of penicillin and $100 \mu \mathrm{g} / \mathrm{ml}$ of streptomycin. All cells were cultured in T-25 flasks and maintained in a humidified atmosphere of 5\% CO2

\section{KARGER}




\section{Cellular Physiology Cell Physiol Biochem 2017;44:1640-1650

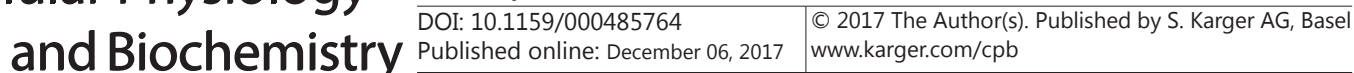

Sun et al.: Celecoxib Suppresses HIF-1 $\alpha$ /VEGF-Mediated Angiogenesis by Targeting

PI3K/AKT Signaling in Retinal Pigment Epithelial Cells

and $90 \%$ relative humidity at $37^{\circ} \mathrm{C}$. The medium was replaced every other day, and the cells were passaged using TrypLE Express after reaching 80\% confluency. Cells were subjected to hypoxic conditions $(1 \%$ 02, $5 \%$ CO2 and 94\% N2) for defined durations of time (3, 6, or $12 \mathrm{hrs).} \mathrm{In} \mathrm{some} \mathrm{experiments,} \mathrm{celecoxib} \mathrm{(Sigma-}$ Aldrich, USA) or LY294002 (Cell Signaling Inc., USA), an inhibitor of PI3K, was added into the D407 cell medium $4 \mathrm{hr}$ before the hypoxic treatment. Baseline data were taken for the cells cultured under normoxic conditions and were defined as hypoxia at $0 \mathrm{hr}$. Experiments were performed on D407 cells at passages 65 to 70 .

\section{3-(4, 5-Dimethylthiazol-2-yl)-2, 5-diphenyltetrazolium bromide (MTT) assays}

The MTT assay was performed to determine the effect of celecoxib on the growth of D407 cells under normoxic or hypoxic condition. Cells were seeded at $1 \times 10^{4}$ cells/well in 96 -well plates and were continuously cultured for $24 \mathrm{hrs}$; then, the cells were subjected to hypoxia and cultured with medium supplemented with $1,10,20$, or $25 \mu \mathrm{M}$ celecoxib for an additional $12 \mathrm{hrs}$. Thereafter, each well was supplemented with $20 \mu \mathrm{L}$ of MTT (5 g/L) (Sigma-Aldrich, USA) and incubated for an additional 4 hrs. The blue formazan produced was solubilized with dimethyl sulfoxide (DMSO, $200 \mu \mathrm{l} /$ well), and the absorbance was measured at $570 \mathrm{~nm}$ by a spectrophotometer. The inhibition of cell growth was calculated according to a published formula [26].

RNA isolation and reverse-transcriptase polymerase chain reaction (RT-PCR)

Total RNA was extracted from cells treated with or without hypoxia by TRIzol reagent (Life Technologies, Glasgow, UK) as described in the manufacturer's protocol. Semi-quantitative RT-PCR assays have been described previously. Reverse transcription was performed with approximately $0.5 \mu \mathrm{g}$ of total RNA, reverse transcriptase (SuperScript II; Life Technologies, Gaithersburg, MD, USA) and 5.0 $\mu$ M oligo-d(T) primer. Aliquots of cDNA were used for PCR amplification with primers specific for HIF- $1 \alpha$, VEGF and $\beta$-actin. The primer sequences were as follows: VEGF (421 bp) 5'- CCTTGCTGCTCTACCTCC-3' and 5'-AAATGCTTTCTCCGCTCT-3'; HIF-1 $\alpha$ (434 bp): 5'-GAAACCACCTATGACCTGC-3' and 5'-CTGTTTGTTGAAGGGAGAA-3'; and $\beta$-actin (472 bp): 5'-AAATCGTGCGTGCGTGACATTAA-3' and 5'-CTCGTCATACTCCTGCTTG-3' (Dalian Bao Bio Co., Ltd., China). Standard PCR amplification was performed as follows: $94^{\circ} \mathrm{C}$ for $5 \mathrm{~min}, 35$ cycles of denaturation at $94^{\circ} \mathrm{C}$ for $45 \mathrm{sec}, 58^{\circ} \mathrm{C}$ for $50 \mathrm{sec}$, and $72^{\circ} \mathrm{C}$ for $40 \mathrm{sec}$ and $10 \mathrm{~min}$ at $72^{\circ} \mathrm{C}$. The amplified products were visualized on $1 \%$ agarose gels. The electrophoretic bands were determined with 100 bp gradient markers (Dalian Bao Bio Co., Ltd., China). The expression levels of target gene mRNA were calculated by normalizing the absorbance of the target gene to that of $\beta$-actin.

\section{Western blot analysis}

Cells were treated with celecoxib or LY294002 and exposed to normoxic or hypoxic conditions for the indicated durations. The cells were collected in radio immunoprecipitation assay (RIPA) buffer and incubated on ice for $30 \mathrm{~min}$. The total protein concentration was measured by a BCA Protein Assay Kit23227 (Pierce Biotechnology). Protein samples (50 $\mu \mathrm{g}$ ) were subjected to $10 \%$ SDS-PAGE and transferred to PVDF membranes (Hybond-C, Amersham and Piscataway, New Jersey, USA). The membranes were blocked with $5 \%(\mathrm{w} / \mathrm{v})$ nonfat milk and probed with rabbit anti-human polyclonal antibody (PI3K 1:400, phosphoAKT 1:400, AKT 1:500, VEGF, 1:300, HIF-1 $\alpha, 1: 200$, and Cox-2 1:400; Santa Cruz Biotechnology, USA) and mouse anti-human $\beta$-actin monoclonal antibody $(1: 400)$ at $4^{\circ} \mathrm{C}$ overnight. The membranes were incubated with goat anti-rabbit alkaline phosphatase-labeled antibody or horse anti-mouse IgG antibody (Santa Cruz, CA, USA). All experiments were repeated in triplicate. Immunoreactive strips were identified using a DAB system (DAB Kit-0031; Maixin Biotechnology Corporation, China) according to the manufacturer's instructions. A bioimaging system (UVP, Upland, CA, USA) was used to capture specific bands, and the optical density (OD) of each band was measured using Image software. The ratio of the OD of the protein of interest and that of $\beta$-actin in each sample was calculated as the relative content and expressed graphically.

\section{Enzyme-linked immunosorbent assay}

Cultures of RPE cells were grown to confluence and treated with $20 \mu \mathrm{M}$ celecoxib for $12 \mathrm{hr}$ in normal or hypoxic conditions. The levels of HIF- $1 \alpha$ and VEGF in the culture supernatants were determined using a VEGF and HIF-1 $\alpha$ ELISA kit (R\&D Systems, USA) according to the manufacturer's instructions

\section{KARGER}


Sun et al.: Celecoxib Suppresses HIF-1 $\alpha$ /VEGF-Mediated Angiogenesis by Targeting PI3K/AKT Signaling in Retinal Pigment Epithelial Cells

\begin{abstract}
Statistical analysis
All data are expressed as the means \pm SD. Statistical differences between two groups were evaluated using unpaired Student's t-test. One-way ANOVA followed by Bonferoni Correction post hoc test for multiple comparisons. A $\mathrm{p}$ value $<0.05$ was considered statistically significant.
\end{abstract}

\section{Results}

Effect of celecoxib on D407 cell proliferation

Hypoxia-mediated cell proliferation is one of the critical factors involved in neovascularization. Thus, we evaluated RPE cell proliferation in the presence of different concentrations of celecoxib $(1,10,20$, or $25 \mu \mathrm{M}$ ) under normoxic or hypoxic conditions for 12 hr. As shown in Fig. 1, the cell proliferation of D407 cells at 10,20 , and $25 \mu \mathrm{M}$ celecoxib was lower than that at $1 \mu \mathrm{M}$ celecoxib $(\mathrm{P}<0.01)$. Celecoxib (20 and $25 \mu \mathrm{M})$ significantly inhibited hypoxia-induced proliferation compared to the proliferation observed under the normoxic condition $(p<0.01)$.

Hypoxia increased HIF$1 \alpha$ and VEGF mRNA expression and the effects of celecoxib on HIF-1 $\alpha$ and VEGF activation

The mRNA expression levels of HIF- $1 \alpha$ and VEGF were examined under normoxic and hypoxic conditions for 3,6 , and 12 hr. A significant increase in HIF-1 $\alpha$ and VEGF mRNA expression was detected

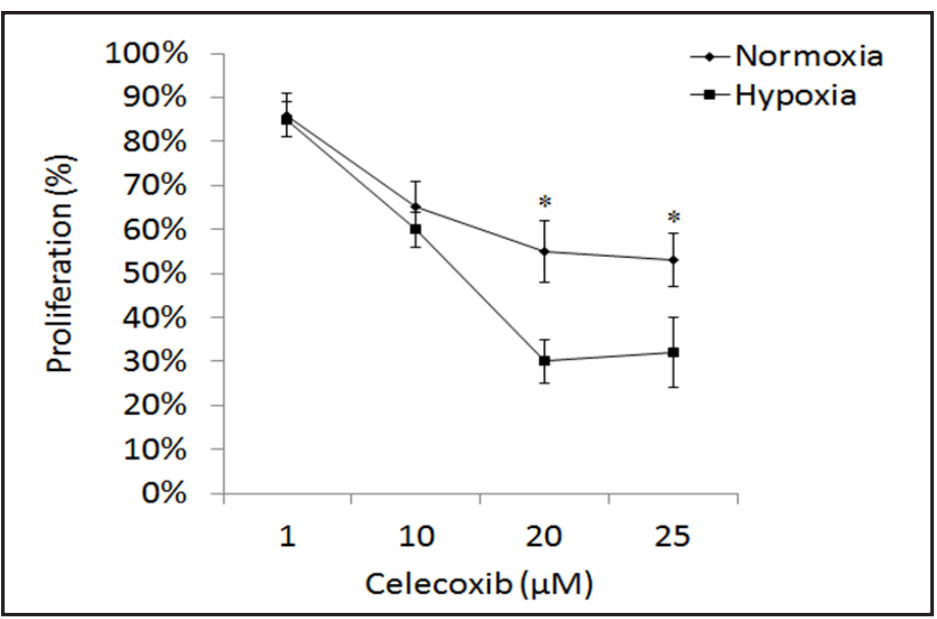

Fig. 1. Effect of celecoxib on RPE cell proliferation under normoxic and hypoxic conditions for $12 \mathrm{hr}$, as evaluated by MTT assay. The growth of RPE cells was inhibited by celecoxib, and the inhibition of cell growth after treatment with celecoxib $(20,25 \mu \mathrm{M})$ under hypoxic conditions was significantly higher than that after treatment with celecoxib under normoxic conditions $\left({ }^{*} \mathrm{P}<0.01\right)$. Statistics: unpaired Student's t-test.

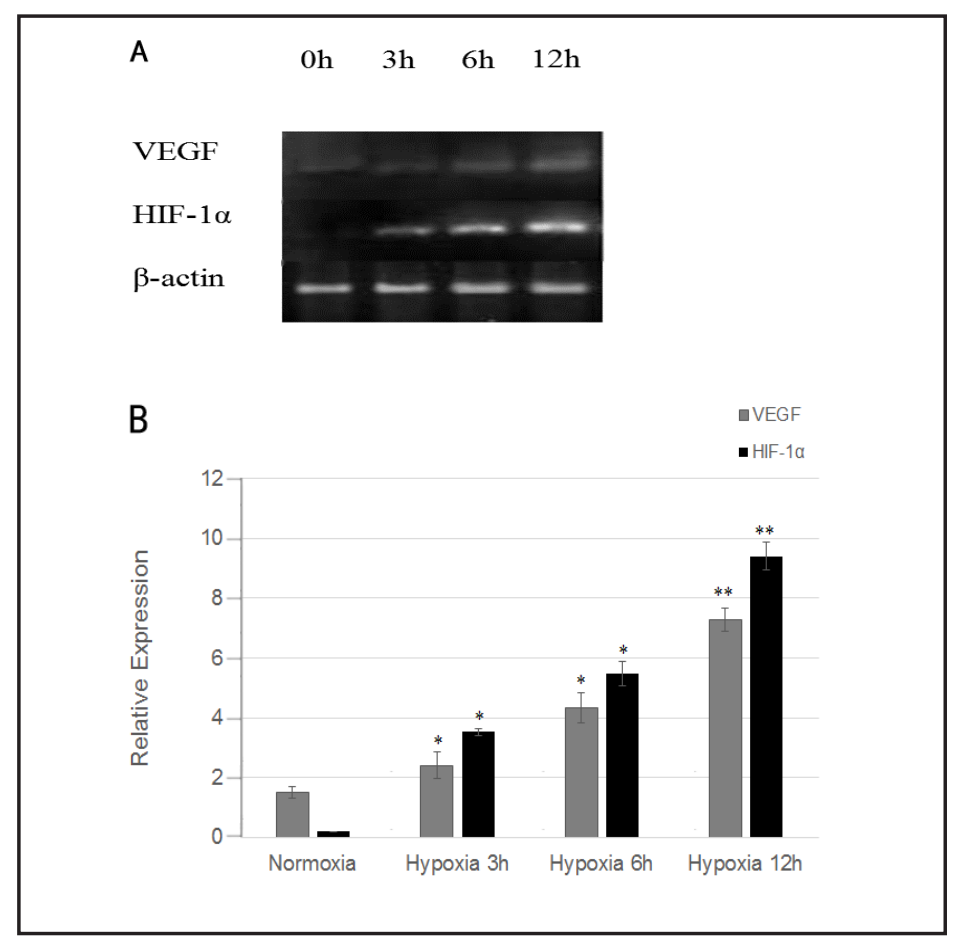

Fig. 2. HIF-1 $\alpha$ and VEGF mRNA expression in RPE cells was detected by semi-quantitative RT-PCR after hypoxic incubation for 3, 6, and 12 h. The total RNA isolated from RPE cells was measured by RT-PCR analysis with HIF- $1 \alpha$ and VEGF specific primers, and $\beta$-actin was used as the internal control. B The quantified data indicate that hypoxic treatment for $3 \mathrm{hr}$ to $12 \mathrm{hr}$ significantly increased the mRNA expression levels of HIF-1 $\alpha$ and VEGF compared with these expression levels in the normoxic group. ${ }^{*} \mathrm{p}<0.05,{ }^{* *} \mathrm{P}<0.01$ compared with normoxia. Statistics: one-way ANOVA with Bonferroni correction. 
Fig. 3. Effects of celecoxib on the mRNA expression of HIF- $1 \alpha$ and VEGF. A RT-PCR was performed to detect the mRNA expression levels. B The quantified data indicate that under hypoxic conditions for $12 \mathrm{~h}$, celecoxib did not alter the mRNA expression levels of HIF- $1 \alpha$. However, celecoxib markedly decreased the mRNA expression of VEGF compared with that of the normoxic group. $\beta$-Actin was used as the internal control. ${ }^{*} \mathrm{p}<$ 0.05 , ${ }^{* *} \mathrm{P}<0.01$ compared with normoxia. $\# \mathrm{P}<$ 0.05 compared with hypoxia. $\mathrm{Cxb}=$ celecoxib. Statistics: one-way ANOVA with Bonferroni correction.

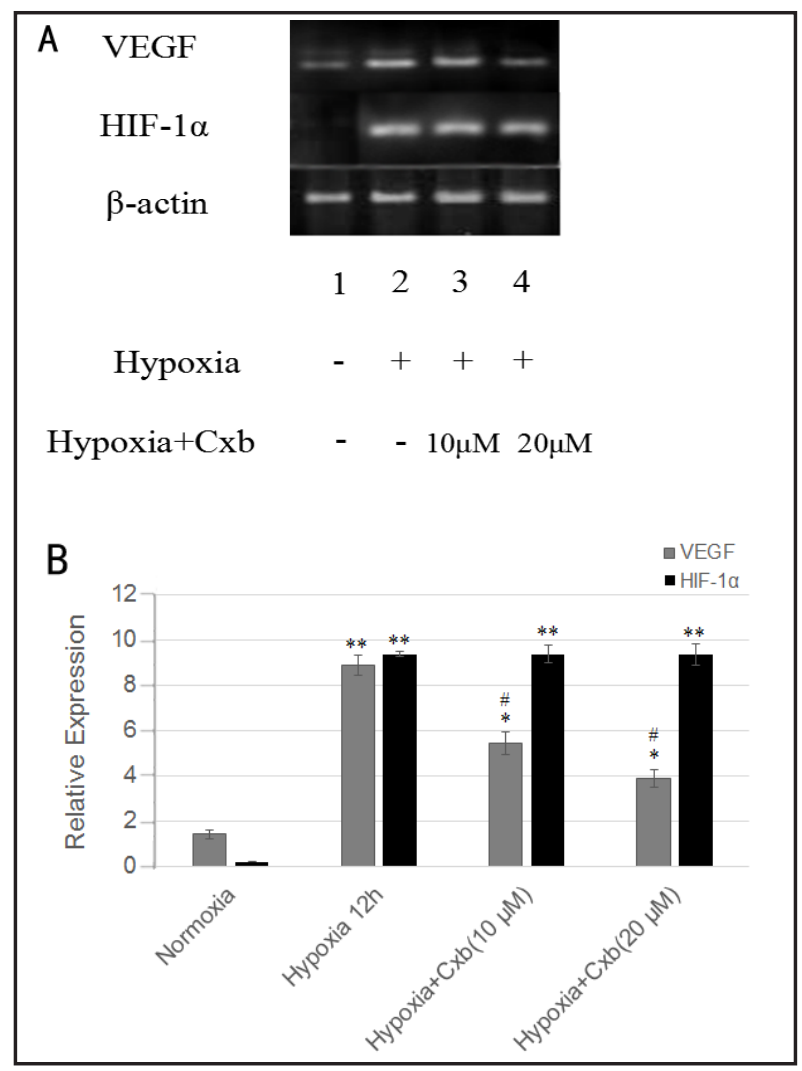

Fig. 4. Hypoxia regulates HIF-1 $\alpha$ expression through PI3K/AKT signaling. The image (A) and quantified data (B) indicate that RPE cells were cultured in normoxia or hypoxia for 12 h. Western blotting was performed to detect the expression of phosphorylated AKT and HIF- $1 \alpha$ and the changes in their expression after treatment with $20 \mu \mathrm{M}$ LY294002 (PI3K inhibitor). ${ }^{* *} \mathrm{P}<0.01$ compared with normoxia. $\# \mathrm{P}<0.05$ compared with hypoxia. LY=LY294002. Statistics: one-way ANOVA with Bonferroni correction.

after exposure to the hypoxic condition for 3 to $12 \mathrm{hr}$ (Fig. 2). Since the expression levels were substantially elevated after exposure to hypoxia for 12 hrs, 12-hr incubations were used for the following experiments.

To verify whether celecoxib can suppress the hypoxia-induced increase in HIF- $1 \alpha$ and VEGF levels, cells were exposed to normoxic and hypoxic conditions with or without celecoxib treatment (10 or $20 \mu \mathrm{M}$ ) for $12 \mathrm{hr}$, and the expression levels of HIF-1 $\alpha$ and VEGF were detected by RT-PCR

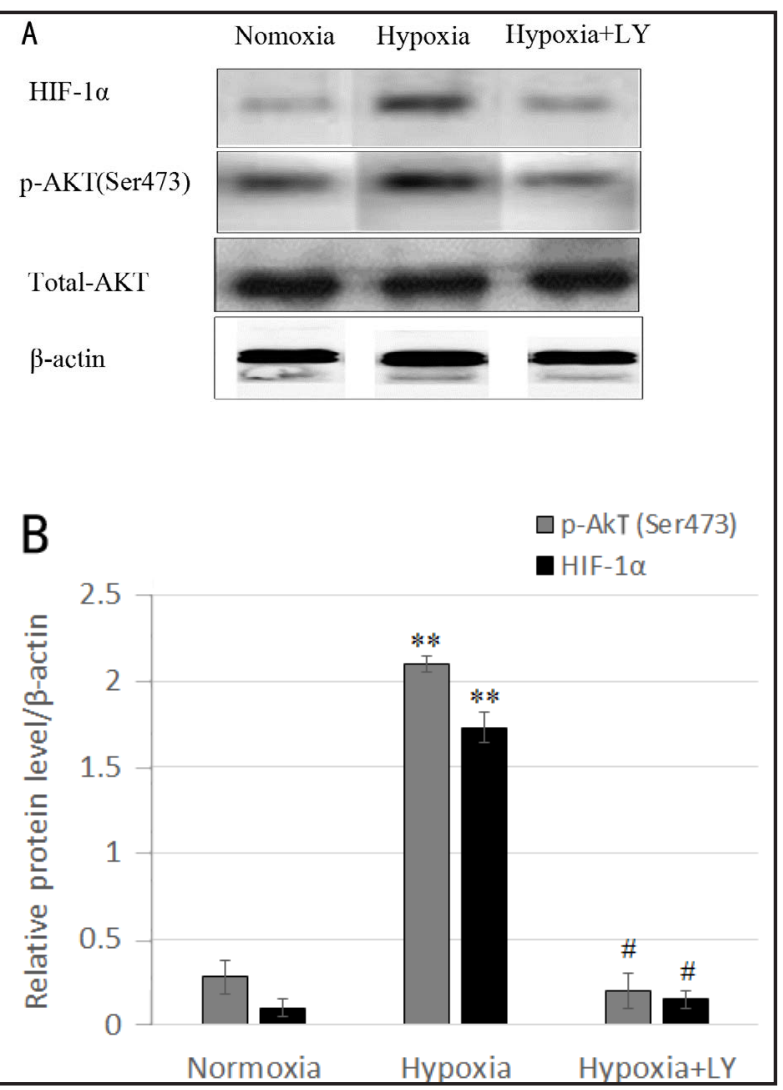
analysis. Celecoxib did not alter the mRNA expression of HIF-1 $\alpha$; however, in D407 cells, 
it significantly reduced the mRNA levels of VEGF in a concentrationdependent manner (Fig. 3).

Celecoxib inhibits HIF-1 $\alpha$ protein accumulation bysuppressing PI3K/AKT signaling

We evaluated whether PI3K/ AKT signaling is involved in hypoxia-induced HIF- $1 \alpha$ activation. As shown in Fig. 4, the level of p-AKT was elevated when RPE cells were cultured in hypoxia for $12 \mathrm{hrs}$, whereas HIF-1 $\alpha$ protein expression was increased, suggesting that hypoxia increased both HIF- $1 \alpha$ and pAKT expression levels. We also investigated whether the PI3K/AKT signaling pathway was involved in the hypoxia-induced increase in HIF- $1 \alpha$ in RPE cells by treating cells with $20 \mu \mathrm{M}$ LY294002 (a PI3K inhibitor) for $12 \mathrm{hr}$ under hypoxia. LY294002 significantly inhibited the increase in HIF- $1 \alpha$ expression in RPE cells exposed in hypoxia (Fig. 4). The data demonstrated that under hypoxic conditions, PI3K/ AKT signaling may be an upstream regulator of HIF- $1 \alpha$ expression in RPE cells. In addition, to verify that PI3K/AKT signaling contributes to the celecoxib-induced decrease in HIF- $1 \alpha$ and VEGF expression, Western blot analysis was performed to assess the activation of PI3K, pAKT, HIF- $1 \alpha$ and VEGF in RPE cells treated with or without $20 \mu \mathrm{M}$ celecoxib under hypoxic conditions for 12 hr. As shown in Fig. 5, in RPE cells exposed to hypoxia for $12 \mathrm{hr}$, celecoxib markedly suppressed the protein expression levels of PI3K, p-AKT, HIF-1 $\alpha$ and VEGF compared to these expression levels in cells under normoxic conditions, indicating that celecoxib treatment suppressed the activation of this pathway and diminished the protein levels of HIF- $1 \alpha$ and VEGF.

Modulation of COX-2 expression in RPE cells treated with celecoxib is through the PI3K/ AKT pathway

To examine if under hypoxic conditions, celecoxib induced the down-regulation of HIF$1 \alpha$ and VEGF protein levels through a COX-2-independent PI3K/AKT pathway we investigated the protein expression of COX-2 under normoxic and hypoxic conditions in the absence or presence of LY294002, celecoxib or LY294002 combined with celecoxib. As shown in Fig. 6, compared to the expression in normoxic conditions, exposure to hypoxia for $12 \mathrm{hr}$ resulted in a marked increase in COX-2 protein expression. Meanwhile, compared with hypoxia,

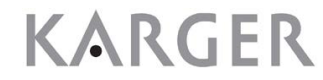


Fig. 6. Regulation of COX-2 expression. Western blot analysis of COX-2 expression in RPE cells untreated or treated with celecoxib alone or combined with LY294002 under normoxia and hypoxia for $12 \mathrm{~h}$. Celecoxib did not down-regulate the expression of COX-2 that was up-regulated by LY294002. Values are presented as the means \pm SD $(n=3) * p<0.05$, compared with normoxia. $\# \mathrm{p}<0.05$, compared with hypoxia, $\mathrm{Cxb}=$ celecoxib. Statistics: one-way ANOVA with Bonferroni correction.

treatment with LY294002 caused a greater increase in COX-2 expression. Surprisingly, the up-regulation of COX-2 protein expression was not impaired in cells treated with celecoxib, which indicated that the down-regulation of HIF-1 $\alpha$ through the PI3K/AKT pathway is independent of COX-2. The results were in accordance with a study by Monick et al. that found that PI3K suppression led to an increase in COX-2 protein expression since PI3K negatively regulates the activation of the p38 pathway [27]. Thus, celecoxib may up-regulate COX2 expression by down-regulating PI3K.

Estimation of HIF-1 $\alpha$ and VEGF Secretion in RPE Cells by ELISA

A marked increase in the secretion of HIF- $1 \alpha$ and VEGF was detected in RPE cells exposed to hypoxia for $12 \mathrm{hrs}$. Compared with the levels in hypoxia, treatment with $20 \mu \mathrm{M}$ celecoxib significantly decreased the secretion of HIF-1 $\alpha$ and VEGF (Fig. 7).

\section{Discussion}

Hypoxia plays a central role in the development and progression of ocular vascular disease. Hypoxia results in the expression of HIF- $1 \alpha$, which regulates VEGF up-regulation under hypoxic conditions [28, 29]. RPE cells can activate the HIF- $1 \alpha$ pathway to release VEGF, initiating angiogenesis in CNV [30, 31].

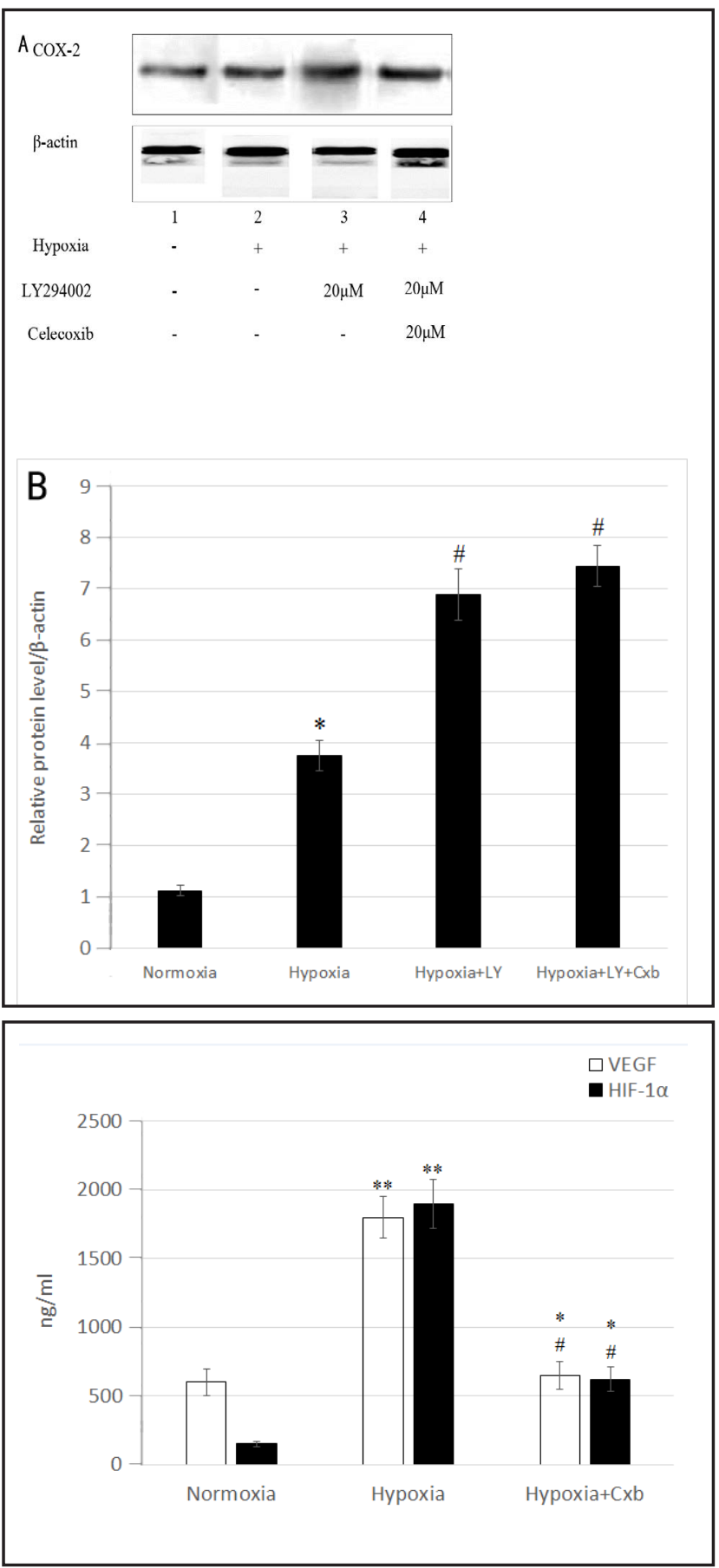

Fig. 7. Effects of celecoxib on HIF- $1 \alpha$ and VEGF secretion from RPE cells (ELISA). After exposure to $20 \mu \mathrm{M}$ celecoxib for 12 hr under hypoxic conditions, a significant decrease in HIF-1 $\alpha$ and VEGF protein expression was detected. ${ }^{*} \mathrm{p}<0.05$, ${ }^{* *} \mathrm{p}<0.01$ compared with normoxia. \#p<0.05, compared with hypoxia. $\mathrm{Cxb}=$ celecoxib. Statistics: one-way ANOVA with Bonferroni correction. 
Sun et al.: Celecoxib Suppresses HIF-1 $\alpha /$ VEGF-Mediated Angiogenesis by Targeting PI3K/AKT Signaling in Retinal Pigment Epithelial Cells

A large number of studies have been conducted to identify inhibitors of the HIF pathway in RPE cells. Lin et al. knocked out HIF- $1 \alpha$ in the RPE using the cre/lox system and suggested that RPE-derived HIF-1 $\alpha$ plays a critical role in CNV [32]. Kurihare et al. demonstrated the off-target effects resulting from the specific knockout of the VEGF gene in adult mice. These knockout mice exhibited degeneration of the choriocapillaris, dysfunctional cone photoreceptors, and ultimately vision loss. However, transcriptional HIF mutants did not elicit any marked secondary off-target effects [33]. The evidence suggests that for the treatment of ocular neovascular diseases, therapeutics targeting the HIF pathway may be an safer, more effective alternative mode of treatment than solely attenuating VEGF levels.

Celecoxib is an anti-inflammatory drug approved for the clinical treatment of adult arthritis. It also has been used in the treatment of various cancers and is currently being investigated for ocular disorders such as AMD and DR due to its anti-proliferative and antiVEGF effects [24, 34, 35]. The molecular mechanisms underlying its inhibitory effects are still unclear. A growing body of experimental evidence suggests that NS398, another COX-2 inhibitor, targets HIF-1 activation and blocks tumor growth [36]. A study by Rismanchi et al. showed that celecoxib can suppress colorectal cancer NV by inhibiting the expression of HIF-1 $\alpha$ [37]. In the present study, we investigated whether celecoxib has the same effects in RPE cells. We demonstrated that hypoxic exposure for $12 \mathrm{hr}$ induced a significant increase in the expression levels of HIF- $1 \alpha$ and VEGF in D407 cells. When RPE cells were cultured in the presence of different concentrations of celecoxib, the hypoxia-induced transcriptional and post-transcriptional increase in VEGF level was inhibited in a concentration-dependent manner. These findings are consistent with the idea that celecoxib may only function as a VEGF inhibitor under hypoxia [38]. In addition, increasing the concentration of celecoxib had significant inhibitory effects on HIF- $1 \alpha$ protein expression. These data clearly signify that the regulation of HIF- $1 \alpha$ stability is a key factor in controlling HIF- $1 \alpha$ protein levels. Hypoxia induces a rapid redox-sensitive increase in HIF-1 protein stability and transcriptional activity, resulting in the activation of target genes involved in erythropoiesis, glycolysis, and angiogenesis [39]. Celecoxib inhibits VEGF expression partly via a HIF- $1 \alpha$ signaling mechanism. Our results are consistent with Palayoor et al. who demonstrated that NSAIDs interfered with HIF1- $\alpha$ protein translation in prostate cancer cells [39].

An active PI3K/AKT/HIF-1 $\alpha$ /VEGF pathway plays a central role in tumorigenesis [40]. Celecoxib is known to inhibit the PI3K/AKT pathway in cancer cell lines [41]. Hence, the PI3K/ AKT signaling pathway has previously been demonstrated to be involved in the hypoxiainduced effects on VEGF and HIF- $1 \alpha$ expression in cancer cell lines. Our data demonstrate that LY294002, a potent PI3K inhibitor, completely inhibited the basal protein expression patterns of HIF- $1 \alpha$, indicating that the PI3K/AKT pathway plays an important role in the maintenance of basal HIF- $1 \alpha$ protein expression, and this is consistent with a study that showed that the PI3K/AKT pathway is required for the hypoxia-induced expression of HIF-1 $\alpha$ and VEGF in laser-induced CNV in rats [42]. Our study found that in RPE cells, the PI3K/AKT pathway was activated in response to hypoxia, suggesting that PI3K/AKT may be a potential therapeutic target for CNV. Pretreating the cells with celecoxib inhibited PI3K/AKT, HIF-1 $\alpha$ and VEGF accumulation, which is in accordance with previous observations that celecoxibtreated cancer cell lines exhibit reduced PI3K/AKT pathway activation, decreased HIF-1 $\alpha$ and VEGF expression, and increased cell apoptosis and proliferation [19]. Together with previous reports, our study shows that suppression of the PI3K/AKT pathway is essential for celecoxib-induced HIF- $1 \alpha$ and VEGF down-regulation in RPE cells.

It should be noted that celecoxib may reduce the elevated HIF- $1 \alpha$ and VEGF expression but does not return them to normal, physiological baseline levels. Furthermore, the incomplete inhibition of HIF- $1 \alpha$ and VEGF up-regulation suggests that aside from hypoxia, other mediators such as NF-kb-mediated COX-2 gene expression and PGE2 production may also contribute to the increased VEGF expression in ocular vascular disease $[43,44]$, and there are other molecular pathways that initiate the hypoxia-induced VEGF expression.

Theoretically, celecoxib should inhibit the expression of COX-2. However, our study found that celecoxib inhibited the PI3K/AKT pathway but up-regulated COX-2 expression, 
instead of down-regulating it as expected, in RPE cells. This finding is consistent with Monick et al [27]. who reported that PI3K inhibition led to an increased level of COX-2 protein and mRNA stability. PI3K negatively regulates the activation of the p38 pathway, and active p38 signaling is necessary for COX-2 production. This is the reason why celecoxib did not suppress but increased COX-2 expression in our study. The down-regulation of PI3K leads to the up-regulation of COX-2 protein levels. Meanwhile, our results also indicate that under hypoxic conditions, celecoxib inhibits RPE cell proliferation and reduces the expression of VEGF through the PI3K/AKT pathway in a COX-2-independent manner.

\section{Conclusion}

Our present study demonstrated that celecoxib inhibited cell growth in a dose-dependent manner. Celecoxib reduced HIF-1 $\alpha$ and VEGF protein expression levels, and this effect may be partly mediated through a PI3K/AKT-dependent, COX-2-independent manner. Collectively, celecoxib-induced VEGF suppression is related to the hypoxia-mediated and angiogenesisrelated PI3K/AKT signaling pathway. Further studies are required to elucidate the apoptosis mechanism of this signaling pathway during the celecoxib-induced suppression of VEGF.

\section{Acknowledgements}

This work was supported by the National Natural Science Foundation of Liaoning Province (No. 20102299).

\section{Disclosure Statement}

The authors declare no conflicts of interest.

\section{References}

1 Kersten E, Paun CC, Schellevis RL, Hoyng CB, Delcourt C, Lengyel I, Peto T, Ueffing M, Klaver CCW, Dammeier S, den Hollander AI, de Jong EK: Systemic and ocular fluid compounds as potential biomarkers in agerelated macular degeneration. Surv Ophthalmol 2017;15:30262-30264.

2 Lai K, Luo C, Zhang X, Ye P, Zhang Y, He J, Yao K: Regulation of angiogenin expression and epithelialmesenchymal transition by HIF-1 $\alpha$ signaling in hypoxic retinal pigment epithelial cells. Biochim Biophys Acta 2016;1862:1594-607.

3 Thom R, Rowe G C , Jang C , Safdar A , Arany Z: Hypoxic induction of vascular endothelial growth factor (VEGF) and angiogenesis in muscleby truncated peroxisome proliferator-activated receptor $\gamma$ coactivator (PGC)-1 $\alpha$. J Biol Chem 2014;289:8810-8817.

-4 Corydon TJ, Mann V, Slumstrup L, Kopp S, Sahana J, Askou AL, Magnusson NE, Echegoyen D, Bek T, Sundaresan A, Riwaldt S, Bauer J, Infanger M, Grimm D: Reduced Expression of Cytoskeletal and Extracellular Matrix Genes in Human Adult Retinal Pigment Epithelium Cells Exposed to Simulated Microgravity.Cell Physiol Biochem 2016;40:1-17.

5 Lavine JA, Farnoodian M, Wang S, Darjatmoko SR, Wright LS, Gamm DM, Ip MS, Sorenson CM, Sheibani N: $\beta 2$-Adrenergic Receptor Antagonism Attenuates CNV Through Inhibition of VEGF and IL-6 Expression. Invest Ophthalmol Vis Sci 2017;58:299-308.

6 Shao J, Choudhary MM, Schachat AP: Neovascular Age-Related Macular Degeneration. Dev Ophthalmol 2016;55:125-136.

7 Huo X, Li Y, Jiang Y, Sun X, Gu L, Guo W, Sun D: Inhibition of ocular neovascularization by co-inhibition of VEGF-A and PLGF.Cell Physiol Biochem 2015;35:1787-1796. 


\section{Cellular Physiology Cell Physiol Biochem 2017;44:1640-1650

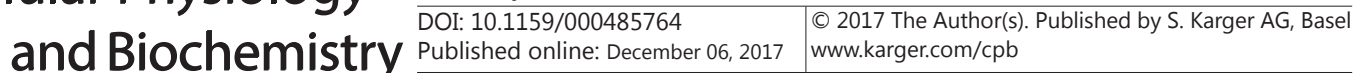

Sun et al.: Celecoxib Suppresses HIF-1 $\alpha$ /VEGF-Mediated Angiogenesis by Targeting PI3K/AKT Signaling in Retinal Pigment Epithelial Cells

8 Wells JA, Murthy R, Chibber R, Nunn A, Molinatti PA, Kohner EM, Gregor ZJ: Levels of vascular endothelial growth factor are elevated in the vitreous of patients with subretinal neovascularisation. Br J Ophthalmol 1996;80:363-366.

-9 Ranjbar M, Brinkmann MP, Zapf D, Miura Y, Rudolf M, Grisanti S: Fc Receptor Inhibition Reduces Susceptibility to Oxidative Stress in Human RPE Cells Treated with Bevacizumab, but not Aflibercept.Cell Physiol Biochem 2016;38:737-747.

10 Gibson JM, Gibson SJ: A safety evaluation of ranibizumab in the treatment of age-related macular degeneration.Expert Opin Drug Saf 2014;13:1259-1270.

11 Mitchell P: A systematic review of the efficacy and safety outcomes of anti-VEGF agents used for treating neovascular age-related macular degeneration: comparison of ranibizumab and bevacizumab. Curr Med Res Opin 2011;27:1465-1475.

12 Cabral T, Lima LH, Polido J, Duong J, Okuda É, Oshima A, Serracarbassa P, Regatieri CV, Belfort RJ: Aqueous vascular endothelial growth factor and clinical outcomes correlation after single intravitreal injection of bevacizumab in patients with neovascular age-related macular degeneration. Int J Retina Vitreous 2017;3:6.

13 Dong X, Wang YS, Dou GR, Hou HY, Shi Y Y, Zhang R, Ma K, Wu L, Yao LB, Cai Y, Zhang J: Influence of Dll4 via HIF- $1 \alpha$-VEGF signaling on the angiogenesis of choroidalneovascularization under hypoxic conditions. PLoS One 2011;19:e18481.

14 André H, Tunik S, Aronsson M, Kvanta A:Hypoxia-Inducible Factor-1 $\alpha$ Is Associated With Sprouting Angiogenesis in the Murine Laser-Induced Choroidal Neovascularization Model.Invest Ophthalmol Vis Sci 2015;56:6591-6604.

15 Seyfried TN, Marsh J, Shelton LM, Huysentruyt LC, Mukherjee P:Is the restricted ketogenic diet a viable alternative to the standard of care for managing malignant brain cancer? .Epilepsy Res 2012;100:310-326.

-16 Wang G, Wang JJ, Fu XL, Guang R, To ST:Advances in the targeting of HIF- $1 \alpha$ and future therapeutic strategies for glioblastoma multiforme (Review). Oncol Rep 2017;37:657-670.

17 Wan J, Wu W, Chen Y, Kang N, Zhang R: Insufficient radiofrequency ablation promotes the growth of nonsmall cell lung cancer cells through PI3K/AKT/HIF-1 a signals. Acta Biochim Biophys Sin (Shanghai) 2016;48:371-377.

18 Kaminska K,Szczylik C, Lian F, Czarnecka A M :The role of prostaglandin E2 in renal cell cancer development: future implications for prognosis and therapy. Future Oncol 2014;10:2177-2187.

19 Sui W , Zhang Y, Wang Z, Jia Q ,Wu L, Zhang W :Antitumor effect of a selective COX-2 inhibitor, celecoxib, may be attributed to angiogenesis inhibition through modulating the PTEN/PI3K/AKT/HIF-1 pathway in an $\mathrm{H}_{22}$ murine hepatocarcinoma model. Oncol Rep 2014;31:2252-2260.

20 Liu B , Shi ZL,Feng J ,Tao HM :Celecoxib, a cyclooxygenase-2 inhibitor, induces apoptosis in human osteosarcoma cell lineMG-63 via down-regulation of PI3K/AKT. Cell Biol Int 2008;32:494-502.

21 Fulda S :The PI3K/AKT/mTOR pathway as therapeutic target in neuroblastoma. Curr Cancer Drug Targets 2009;9:729-737.

22 Castro MR, Lutz D , Edelman J L: Effect of COX inhibitors on VEGF-induced retinal vascular leakage and experimentalcornealand choroidal neovascularization. Exp Eye Res 2004; 79:275-285.

$\checkmark 23$ Liu NN, Sun YZ, Zhao N, Chen L :Rofecoxib inhibits retinal neovascularization via down regulation of cyclooxygenase-2 and vascular endothelial growth factor expression. Clin Exp Ophthalmol 2015;43:458465.

24 Liu N, Chen L, Cai N:Celecoxib attenuates retinal angiogenesis in a mouse model of oxygen-induced retinopathy. Int J Clin Exp Pathol 2015;8:4990-4998.

25 Amrite AC, Kompella U B :Celecoxib inhibits proliferation of retinal pigment epithelial and choroid-retinal endothelialcells by a cyclooxygenase-2-independent mechanism.J Pharmacol Exp Ther 2008;324:749-758.

26 Chen QJ , Zhang MZ, Wang LX:Gensenoside Rg3 inhibits hypoxia-induced VEGF expression in human cancer cells. Cell Physiol Biochem 2010;26:849-858.

-27 Monick MM, Robeff PK,Butler NS, Flaherty DM , Carter AB, Peterson MW , Hunninghake GW : Phosphatidylinositol 3-kinase activity negatively regulates stability of cyclooxygenase 2 mRNA. J Biol Chem 2002;277:2992-3000.

28 Wei J, Jiang H, Gao H, Wang G: Blocking Mammalian Target of Rapamycin (mTOR) Attenuates HIF-1 a Pathways Engaged-Vascular Endothelial Growth Factor (VEGF) in Diabetic Retinopathy. Cell Physiol Biochem 2016;40:1570-1577. 


\section{Cellular Physiology Cell Physiol Biochem 2017;44:1640-1650 \begin{tabular}{l|l|l} 
and Biochemistry & DOI:1159/000485764 & $\begin{array}{l}\text { C) } 2017 \text { The Author(s). Published by S. Karger AG, Basel } \\
\text { www.karger.com/cpb }\end{array}$ \\
\hline
\end{tabular}

Sun et al.: Celecoxib Suppresses HIF-1 $\alpha$ /VEGF-Mediated Angiogenesis by Targeting PI3K/AKT Signaling in Retinal Pigment Epithelial Cells

-29 Feng Y, Gross S, Chatterjee A, Wang Y, Lin J, Hammes HP: Transcription of Inflammatory Cytokine TNF a is Upregulated in Retinal Angiogenesis under Hyperoxia.Cell Physiol Biochem 2016;39:573-583

-30 Dong X, Wang YS, Dou GR, Hou HY, Shi YY, Zhang R, Ma K, Wu L, Yao LB, Cai Y, Zhang J: Influence of Dll4 via HIF-1 $\alpha$-VEGF signaling on the angiogenesis of choroidal neovascularization under hypoxic conditions. PLoS One 2011;6:e18481.

31 Liu X, Zhu M, Yang X, Wang Y, Qin B, Cui C, Chen H, Sang A: Inhibition of RACK1 ameliorates choroidal neovascularization formation in vitro and in vivo. Exp Mol Pathol 2016;100:451-459.

-32 Lin M, Hu Y, Chen Y, Zhou KK, Jin J , Zhu M, Le YZ, Ge J , Ma JX : Impacts of hypoxia-inducible factor-1 knockout in the retinal pigment epithelium on choroidalneovascularization. Invest Ophthalmol Vis Sci 2012;53:6197-6206.

-33 Kurihara T, Kubota Y, Ozawa Y, Takubo K, Noda K, Simon MC, Johnson RS, Suematsu M, Tsubota K, Ishida S, Goda N, Suda T, Okano H:von Hippel-Lindau protein regulates transition from the fetal to the adult circulatory system inretina. Development 2010;137:1563-1571.

-34 Ayalasomayajula SP, Kompella UB : Celecoxib,a selective cyclooxygenase-2 inhibitor, inhibits retinal vascular endothelial growthfactor expression and vascular leakage in a streptozotocin-induced diabetic rat model. Eur J Pharmacol 2003;458:283-289.

-35 Hu W, Criswell MH, Ottlecz A, Cornell TL, Danis RP, Lambrou GN,Ciulla TA:Oral administration of lumiracoxib reduces choroidal neovascular membrane development in the rat laser-trauma model. Retina 2005;25:1054-1064.

36 Zhong H, Willard M, Simons J:NS398 reduces hypoxia-inducible factor (HIF)-1alpha and HIF-1 activity: multiple-level effectsinvolving cyclooxygenase-2 dependent and independent mechanisms.Int J Cancer 2004;112:585-595.

37 Rismanchi S, Mortazavi P, Amanpour S: The role of selective Cox-2 inhibitors on HIF-1 alpha gene in colorectal cancer: an in-vitro study.Tehran Univ Med J 2014;72:443-448.

-38 Wei D, Wang L, He Y, Xiong HQ Abbruzzese JL, Xie K: Celecoxib inhibits vascular endothelial growth factor expression in and reducesangiogenesis and metastasis of human pancreatic cancer via suppression of Sp1transcription factor activity. Cancer Res 2004;64:2030-2038.

-39 Palayoor ST, ofilon PJ, Coleman CN: Ibuprofen-mediated reduction of hypoxia-inducible factors HIF-1alpha and HIF-2alpha in prostate cancer cells. Clin Cancer Res 2003;9:3150-3157.

40 Zhang J, Su H, Li Q Li J, Zhao Q: Genistein decreases A549 cell viability via inhibition of the PI3K/AKT/ HIF-1 $\alpha /$ VEGF and NF- $\mathrm{BB} / \mathrm{COX}-2$ signaling pathways. Mol Med Rep 2017;15:2296-2302.

41 Liu M, Li CM, Chen ZF, Ji R, Guo QH, Li Q, Zhang HL, Zhou Y N :Celecoxib regulates apoptosis and autophagy via the PI3K/AKT signaling pathway in SGC-7901 gastric cancer cells. Int J Mol Med 2014;33:1451-1458.

-42 Yang XM, Wang YS, Zhang J, Li Y, Xu JF, Zhu J, Zhao W, Chu DK,Wiedemann P:Role of PI3K/AKT and MEK/ ERK in mediating hypoxia-induced expression of HIF-1alpha and VEGF in laser-induced rat choroidal neovascularization. Invest Ophthalmol Vis Sci 2009;50:1873-1879.

-43 Medeiros R, Rodrigues GB, Figueiredo CP, Rodrigues EB, Grumman AJr, Menezes-de-Lima OJr, Passos GF, Calixto JB:Molecular mechanisms of topical anti-inflammatory effects of lipoxin A(4) in endotoxin-induced uveitis.Mol Pharmacol 2008;74:154-161.

-44 Yanni SE, Barnett JM, Clark ML, Penn JS:The role of PGE2 receptor EP4 in pathologic ocular angiogenesis. Invest Ophthalmol Vis Sci 2009;50:5479-5486. 